\title{
MODELING OF FULL PHOTOVOLTAIC SYSTEMS APPLIED TO ADVANCED CONTROL STRATEGIES
}

\author{
Carlos Andrés Ramos-Paja ${ }^{1}$, Efraín Pérez ${ }^{1}$, Daniel González Montoya ${ }^{1}$, \\ Carlos E. Carrejo ${ }^{2}$, Adan Simon-Muela ${ }^{4}$, Corinne Alonso ${ }^{2,3}$ \\ Escuela de Mecatrónica, Universidad Nacional de Colombia - sede Medellín, Colombia ${ }^{1}$ \\ LAAS-CNRS, 7 Avenue du Colonel Roche, F-31077, Toulouse, France ${ }^{2}$ \\ Université de Toulouse; UPS, INSA, INP, ISAE, LAAS, F-31077, Toulouse, France ${ }^{3}$ \\ Electronic Engineering Department, Universidad de Sevilla, Spain ${ }^{4}$
}

\begin{abstract}
Nowadays, different control strategies, to regulate Photovoltaic (PV) maximum power point are available. This paper is focused on the modeling of PV power conversion chains considering the $P V$ panel, its associated power conversion stage and the load as a sole system. Furthermore, two control strategies have been proposed for the resulting non-linear system. These controllers are calculated to mitigate input and load disturbances. In addition, the proposed model and its underlying control strategy is used with a P\&O MPPT algorithm to show the feasibility in advanced control strategies for PV systems.
\end{abstract}

\section{Introduction}

There is a strong perception of a future high worldwide demand for energy. In the few past years, dwindling fossil-fuel reserves and climate change foster the use of renewable power supplies in order to decrease global warming. One of the candidates to replace pollutant fossil-fuel energy sources is Photovoltaic (PV) energy. This renewable source is becoming more and more important for either standalone or grid-connected systems. Therefore, a typical PV power conversion chain is shown in Fig. 1 [1].

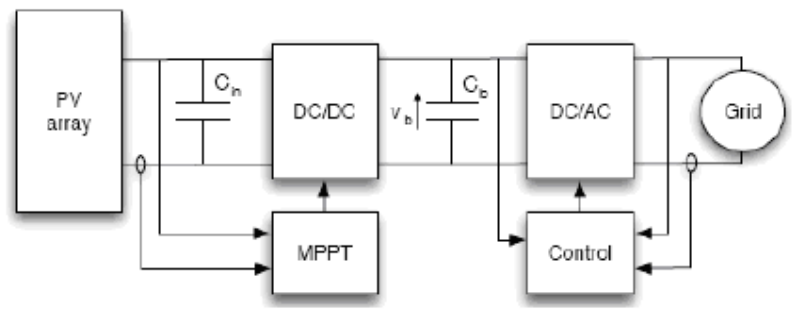

Fig. 1 Grid-connected PV power conversion chain

In the previous system, the main objective of the control strategy is to impose a desired voltage in the PV panel output and therefore, in the power converter input capacitor, $\mathrm{C}_{\mathrm{in}}$.

In the previous PV power conversion chain, the left part composed of the PV panel and the DC/DC power converter, can be considered as a closed-loop system. This closed-loop system must be able to reject input (irradiance) and load (DC/AC inverter) disturbances. In doing so, two cases must be studied. The first possibility is related to the single-phase inverter regulation of the bulk capacitor DC voltage, $\mathrm{C}_{\mathrm{b}}$. In this case, the output voltage of the DC/DC power converter is disturbed by a sinusoidal voltage, voltage load perturbation. ${ }^{1}$ The magnitude of this disturbance is inversely proportional to the $C_{b}$ value. As a result, this oscillation can be significant since $C_{b}$ owns normally high values. Moreover, $\mathrm{C}_{\mathrm{b}}$ electrolytic technology is currently used. In general terms, electrolytic capacitors are expensive and own reduced reliability [2]. The voltage oscillation introduced in this has a frequency that is twice as gridfrequency [3].

In the second case, the inverter absorbs sinusoidal current (current load perturbation, IZ). This current generates an undesirable oscillation, owning different frequency values in the DC/DC converter output voltage. This oscillation disturbs the maximum power point tracker placed at the power converter input. For that matter, an appropriate control strategy must be applied to mitigate this oscillation [3].

This work proposes the modeling of different control strategies to regulate $C_{b} D C$ voltage. One key point of these control laws is to approach the inverter depending on the final specifications. For instance, in the first approach, the inverter is considered as a sinusoidal voltage source with a DC average imposed by the control strategy. In the second case study, the inverter is considered as an impedance in parallel with a sinusoidal current source. This last current source weights the injected power in the grid.

Therefore, the main motivation of this paper is to propose the modeling of a sole system composed of the PV panel, its associated DC/DC power converter and the load (inverter) as a full system. Thanks to this global approach, the design of advanced control strategies to regulate the PV panel output voltage can be more optimized. This increase of the accuracy is obtained thanks to a finer characterization of the electrical source and its adaptation stage. For instance, aforementioned control strategies have been theoretically analyzed designed and validated using PSIM numerical simulations. Furthermore, these control laws require a $\mathrm{P} \& O$ MPPT algorithm [6] to regulate the $\mathrm{C}_{\mathrm{in}}$ and, therefore the PV panel voltage.

Five sections compose this paper. To begin with the theoretical work, section II describes the IZ control strategy case, to regulate the $C_{b} D C$ voltage. The main goal of this control law is to mitigate voltage oscillations caused by the inverter. Section III describes the modeling of the system including the VZ control strategy. This second approach is a particular case of the first one. The simulation results, considering detailed PV panel and power converter models are described in section IV. These results validate the theoretical analysis exposed in 
previous sections. Finally, conclusions are presented in the last section.

\section{Modeling of the PV system considering an IZ control of the bulk capacitor DC voltage}

\subsection{Modeling of the global system}

The modeling of the PV panel and its associated power conversion, considering IZ control, is described in this section.

Fig. 2 shows the electrical circuit of the proposed system; i.e. the PV panel and the conditioning power stage (DC/DC power converter) and IZ controller. As it has been previously explained, both systems are considered as a sole system.

As regards the power converter, a step-up Boost topology has been chosen since $\mathrm{C}_{\mathrm{b}}$ voltage must be necessarily higher than the PV panel output voltage. This power converter is a common choice due to its high efficiency, low complexity, simple control and reduced cost.

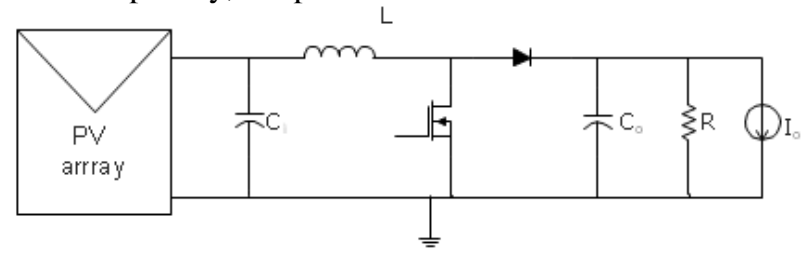

Fig. 2 PV panel $+D C / D C$ power converter electrical schema for the IZ control approach

To begin with the modeling of the system, inductor current $\left(\mathrm{I}_{\mathrm{L}}\right)$ input $\left(\mathrm{V}_{\mathrm{ci}}\right)$ and output $\left(\mathrm{V}_{\mathrm{co}}\right)$ capacitor voltages have been chosen as state variables. Moreover, control variables are the power converter duty-cycle $(\mathrm{d}, 0 \leq \mathrm{d} \leq$ $1)$, the PV panel short-circuit current $\left(\mathrm{I}_{\mathrm{sc}}\right)$ and the load current $\left(\mathrm{I}_{0}\right)$. This last variable describes load disturbances caused by the inverter.

Fig. 3 depicts the PV panel Norton model. This model illustrates the PV panel small-signal behavior working at its Maximum Power Point (MPP) for a given irradiance [7].

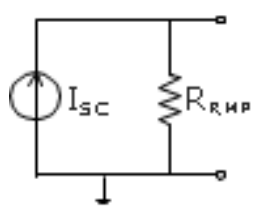

Fig. 3 PV panel Norton (small-signal) model

Starting with the system modeling, the ON semi-period (d) is defined by the time when main power converter switch is closed; i.e. the MOSFET is turned ON. Hence, the equations describing the system behavior are:

$v_{L}=v_{C_{i}}=L \frac{d i_{L}}{d t}$

$i_{C i}=I_{s c}-\frac{v_{C i}}{R_{M P}}=C_{i} \frac{d v_{C i}}{d t}$

$i_{C o}=-\frac{V}{R}-I_{o}=C_{o} \frac{d v_{C o}}{d t}$
When the control signal is turned off, the diode is now on conduction. Thus, the OFF semi-period (1-d) starts. Next equations describe the system behavior:

$$
\begin{aligned}
& v_{L}=v_{C_{i}}-v_{C o}=L \frac{d i_{L}}{d t} \\
& i_{C i}=I_{s c}-\frac{v_{C i}}{R_{M P}}-i_{L}=C_{i} \frac{d v_{C i}}{d t} \\
& i_{C o}=i_{L}-\frac{V}{R}-I_{o}=C_{o} \frac{d v_{C o}}{d t}
\end{aligned}
$$

The system state-space behavior can be described by a set of matrix:

$\dot{X}=A X+B U$

$Y=C X+D U$

where:

$$
X=\left\lfloor\begin{array}{c}
i_{L} \\
v_{C i} \\
v_{C o}
\end{array}\right\rfloor, \quad U=\left[\begin{array}{c}
d \\
I_{s c} \\
I_{o}
\end{array}\right], C=\left[\begin{array}{l}
0 \\
1 \\
0
\end{array}\right]^{T}, D=\left[\begin{array}{l}
0 \\
0 \\
0
\end{array}\right]^{T}, Y=\left[v_{C i}\right]
$$

On the one hand, A matrix, described in (13), represents the derivative of the states depending on the states; i.e. the Jacobin's states. On the other hand, B matrix, described in (14), represents the derivative of the states depending on the system inputs; i.e. the Jacobin's inputs. Moreover, $\mathrm{C}$ matrix imposes the output capacitor voltage as the system output (Y). It can be observed that D matrix is zero from equations (10) to (12).

Applying inductor volt-second balance (average model) to previous state equations, $\mathrm{A}$ and $\mathrm{B}$ matrixes are found [3]:

$$
\dot{i_{L}}=\frac{v_{C i}}{L}-\frac{v_{C o} \cdot(1-d)}{L}
$$

After, a charge balance is applied to input $\left(\mathrm{C}_{\mathrm{i}}\right)$ and output capacitors $\left(\mathrm{C}_{\mathrm{o}}\right)$ :

$$
\begin{aligned}
& \dot{v_{C i}}=\frac{1}{C_{i}} \cdot\left(I_{s c}-\frac{v_{C i}}{R_{M P}}-i_{L}\right) \\
& \dot{v_{C o}}=\frac{1}{C_{o}} \cdot\left(i_{L} \cdot(1-d)-\frac{v_{C o}}{R}-I_{o}\right)
\end{aligned}
$$

Using (10), (11) and (12) in (7), A and B matrixes are obtained:

$$
\begin{aligned}
& A=\left[\begin{array}{ccc}
0 & \frac{1}{L} & -\frac{(1-d)}{L} \\
-\frac{1}{C_{i}} & -\frac{1}{C_{i} \cdot R_{M P}} & 0 \\
\frac{(1-d)}{C_{o}} & 0 & -\frac{1}{C_{o} \cdot R}
\end{array}\right] \\
& B=\left[\begin{array}{ccc}
\frac{v_{C o}}{L} & 0 & 0 \\
0 & \frac{1}{C_{i}} & 0 \\
\frac{-i_{L}}{C_{o}} & 0 & -\frac{1}{C_{o}}
\end{array}\right]
\end{aligned}
$$

The resulting system is not linear. As a result, the next step is to obtain the linear model [5]. For that matter, the equilibrium point is found by making zero (10) to (12). $V_{C i}=V_{C o} \cdot(1-D)$

$I_{L}=I_{s c}-\frac{V_{C i}}{R_{M P}}$ 
$I_{L} \cdot(1-D)=\frac{V_{C o}}{R}+I_{o}$

Working out previous system of equations, the required steady-state duty-cycle value (D) is found in (18)

$$
1-D=\frac{I_{o}+\sqrt{I_{o}{ }^{2}+4 \cdot\left(\frac{V_{C i}}{R}\right) \cdot\left(I_{s c}-\frac{V_{C i}}{R_{M P}}\right)}}{2 \cdot\left(I_{s c}-\frac{V_{C i}}{R_{M P}}\right)}
$$

From a physical standpoint, $D$ must own a value comprised in-between $[0,1]$. As a consequence, $\mathrm{I}_{\mathrm{sc}}$ limits the maximum PV panel output current as follows:

$$
I_{S C}>\left[\frac{V_{C I}}{R_{M P}}\right]
$$

\subsection{Design of the controller to regulate $\mathrm{C}_{\mathrm{b}}$ voltage.}

The following parameters have been used for the design of the controller: $\mathrm{L}=100 \mu \mathrm{H}, \mathrm{C}_{\mathrm{i}}=50 \mu \mathrm{F}, \mathrm{C}_{\mathrm{o}}=50 \mu \mathrm{F}$, $\mathrm{V}_{\mathrm{dc}}=48 \quad \mathrm{~V}, \quad \mathrm{I}_{\mathrm{sc}}=4.8 \quad \mathrm{~A}, \quad \mathrm{R}_{\mathrm{mp}}=1.978 \quad \Omega, \quad \mathrm{R}=100 \quad \Omega$, $\mathrm{V}_{\mathrm{cmp}}=9.178 \mathrm{~V}, \mathrm{f}_{\mathrm{sw}}=50 \mathrm{kHz}$ (switching frequency).

Polarization (I-V) and PV power $(\mathrm{P}-\mathrm{V})$ curves are represented in Fig. 4. Note that the panel owns a $\mathrm{I}_{\mathrm{sc}}=4.8$ $\mathrm{A}$ and $\mathrm{a} \mathrm{V}_{\mathrm{oc}}=10.6 \mathrm{~V}$ (open-circuit voltage) for $\mathrm{a}$ maximum $\mathrm{S}_{1}=960 \mathrm{~W} / \mathrm{m}^{2}$ irradiance. It can be also observed that the $\mathrm{PV}$ panel delivers $\mathrm{P}_{\mathrm{pv}}=40.75 \mathrm{~W}$ $\left(\mathrm{V}_{\mathrm{mp}}=9.15 \mathrm{~V}, \mathrm{I}_{\mathrm{mp}}=4.45 \mathrm{~A}\right)$ maximum power for this irradiance value. Similarly, $22.77 \mathrm{~W} \quad\left(\mathrm{~V}_{\mathrm{mp}}=8.79 \mathrm{~V}\right.$, $\mathrm{I}_{\mathrm{mp}}=2.59$ A) can be obtained for $\mathrm{S}_{2}=560 \mathrm{~W} / \mathrm{m}^{2}$ irradiance.

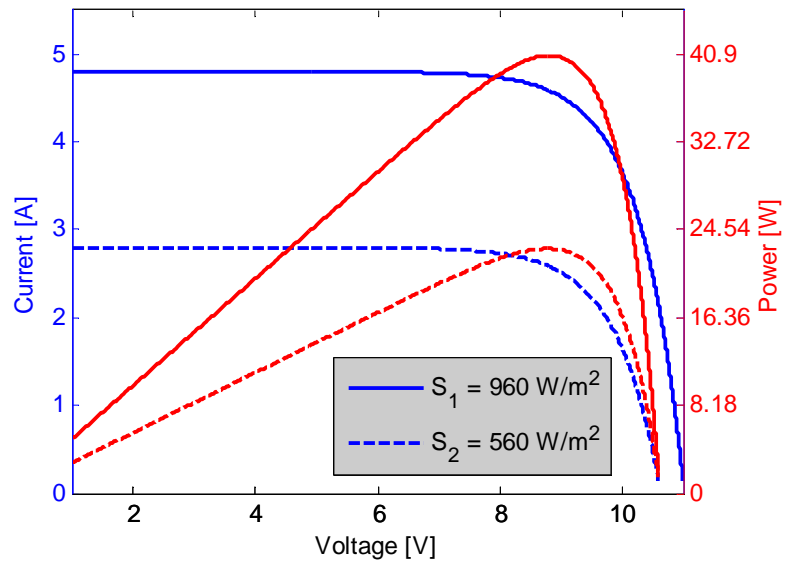

Fig. 4 I-V (blue) and P-V (red) curves for the PV panel

The operating point of previous linear model is calculated using aforementioned parameters. Therefore, the system stability is parsed by means of the root-locus technique, where it is concluded that the system exhibits a nonminimum phase behavior. Consequently, PI and PID controllers cannot be used due to stability issues.

The solution adopted is to design a current controller assuring null inductor-current steady state error. The design specifications imposed are a 0.707 damping factor and a $10 \mathrm{kHz}$ minimal bandwidth. These requirements assure a closed-loop gain lower than $0 \mathrm{~dB}$ at the switching frequency value [4]. In doing so, the lineal model is valid since the frequency spectrum of the closed loop system is below the switching frequency. The controller transfer function is described in (20).
$G_{C 1}(s)=1.395 \times 10^{-5} \frac{s^{2}+4.931 \times 10^{4} s+8.652 \times 10^{8}}{s}$

In this case study, some transfer functions must be certainly defined:

- $T_{\text {iLiref: }}$ reference-to-inductor current transfer function.

- $\mathrm{T}_{\mathrm{iLIsc}}$ : short-circuit current-to-inductor current transfer function.

- $\mathrm{T}_{\mathrm{iLIo}}$ : load current-to-inductor current transfer function.

Closed-loop frequency responses for these transfer functions are represented in Fig. 5. This figure validates the tracking of the reference by the inductor current in the desired range; i.e. up to $10 \mathrm{kHz}$. Furthermore, it can be observed short-circuit current and load disturbance rejections. This feature is particularly important to reject (28.35dB attenuation factor) $100 \mathrm{~Hz}$ load disturbances (for $50 \mathrm{~Hz}$ grid-connected systems) in the $\mathrm{C}_{\mathrm{b}} \mathrm{DC}$ voltage. This disturbance comes from the inverter. However, the significant attenuation factor mitigates disturbance effects in the inductor current. This is particularly important when non-electrolytic capacitors are used since the voltage oscillations are significant [3].

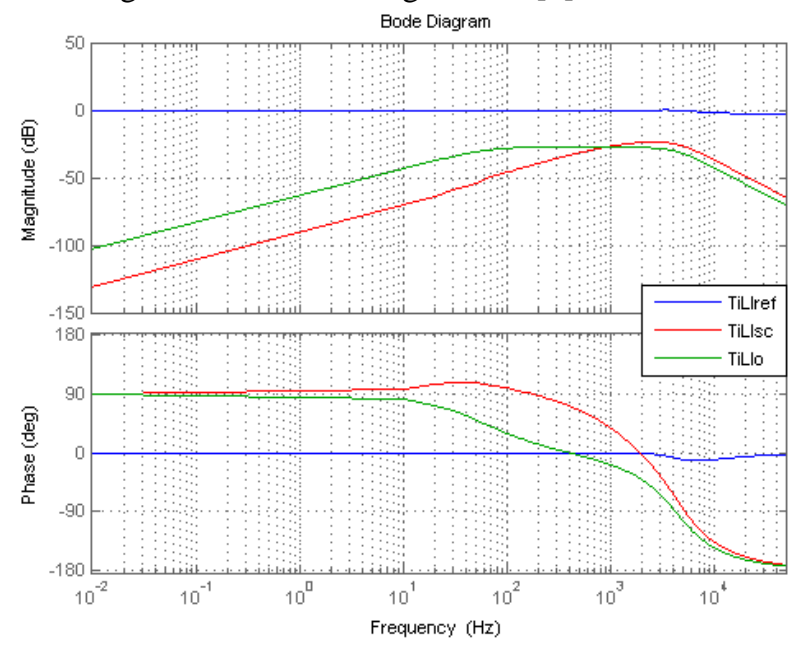

Fig. 5 Closed-loop frequency gain responses for the inductor-current controlled system

The next step is to design a new linear model taking into account this inductor-current control as a currentcontrolled source $\left(\mathrm{I}_{\text {ref }}\right)$. The control design goal is now to regulate the input capacitor voltage $\left(\mathrm{C}_{\mathrm{in}}\right)$. This new model is illustrated in Fig. 6.

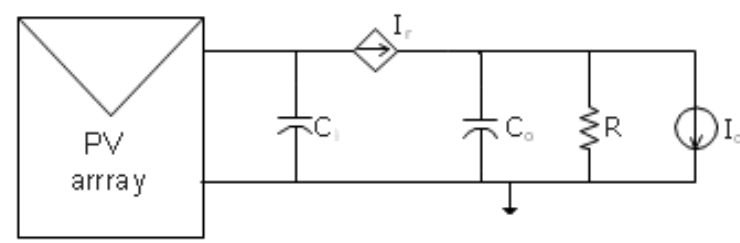

Fig. 6 PV panel + power converter model considering inductor-current control as a current-controlled source

Applying the same analysis of the previous case, the set of equations describing the system behavior can be formulated. Now, the system output is the input capacitor voltage and state variables are:

- $\mathrm{v}_{\mathrm{Ci}}$ : input capacitor voltage

- $\mathrm{v}_{\mathrm{Co}}$ : output capacitor voltage

Correspondingly, system inputs are: 
- $\mathrm{I}_{\text {ref }}$ : Inductor-current reference

- $\mathrm{I}_{\mathrm{sc}}$ : PV Panel short-circuit current

- $\mathrm{I}_{\mathrm{o}}$ : load current

$A=\left[\begin{array}{cc}-\frac{1}{C_{i} \cdot R_{M P}} & 0 \\ 0 & -\frac{1}{C_{o} \cdot R}\end{array}\right]$

$B=\left[\begin{array}{ccc}-\frac{1}{C_{i}} & \frac{1}{C_{i}} & 0 \\ \frac{1}{C_{o}} & 0 & -\frac{1}{C_{o}}\end{array}\right]$

$X=\left\lfloor\begin{array}{l}v_{C i} \\ v_{C o}\end{array}\right\rfloor, U=\left[\begin{array}{c}I_{r e f} \\ I_{s c} \\ I_{o}\end{array}\right], C=\left[\begin{array}{l}1 \\ 0\end{array}\right]^{T}, D=\left[\begin{array}{l}0 \\ 0 \\ 0\end{array}\right]^{T}, Y=\left[v_{C i}\right]$

In this case, a PI controller (24) has been designed to regulate $\mathrm{v}_{\mathrm{Ci}}$ voltage. Design requirements are now $\mathrm{t}_{\mathrm{s}}=1$ ms settling time, 0.707 damping factor and null steadystate error.

$G_{C 2}(s)=-0.8063 \frac{s+1.429 \times 10^{4}}{s}$

As result, the new model has two control loops; i.e. an inner inductor-current control and an external voltage loop. In short, the following transfer functions are formulated. Fig. 7 depicts their closed-loop gain frequency responses:

- $\mathrm{T}_{\mathrm{VV} \text { ref }}$ : reference-to-input capacitor voltage transfer function

- $\mathrm{T}_{\mathrm{VIsc}}$ : short-circuit current-to-input capacitor voltage transfer function

- $\mathrm{T}_{\mathrm{VIo}}$ : load-to-input capacitor voltage transfer function The accurate tracking of the input-capacitor voltage can be observed in the desired frequency range; i.e. up to 1 $\mathrm{kHz}$. Furthermore, input and output disturbances are considerably rejected; e.g. $-30 \mathrm{~dB}$ at $100 \mathrm{~Hz}$.

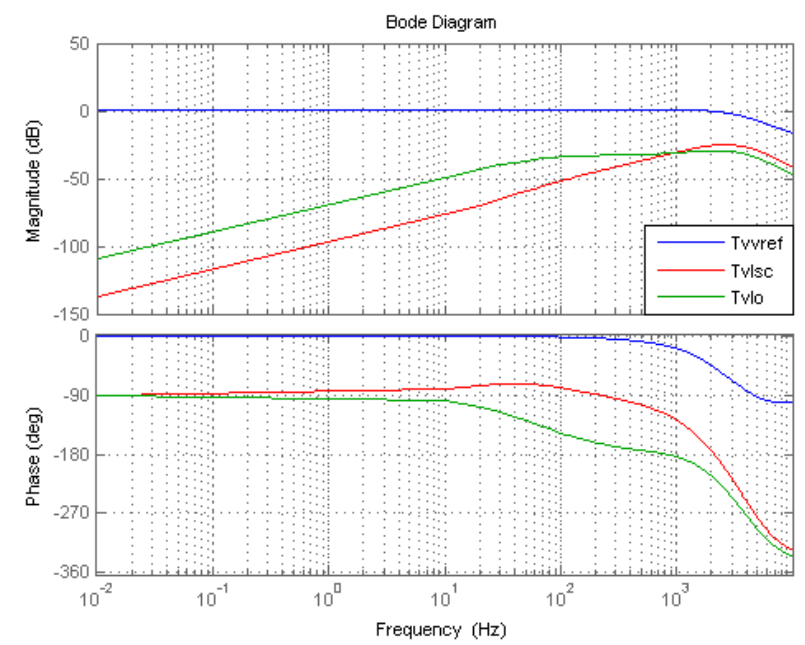

Fig. 7 Closed-loop gain frequency responses for the two control loops system

\section{Modeling of the PV system considering a VZ control of the bulk capacitor DC voltage}

This section presents the modeling of a VZ control to regulate the Bulk capacitor DC voltage. In this approach, the DC/AC inverter is considered as a source voltage which owns $100 \mathrm{~Hz}$ DC and AC components. Fig. 8 depicts the presented model.

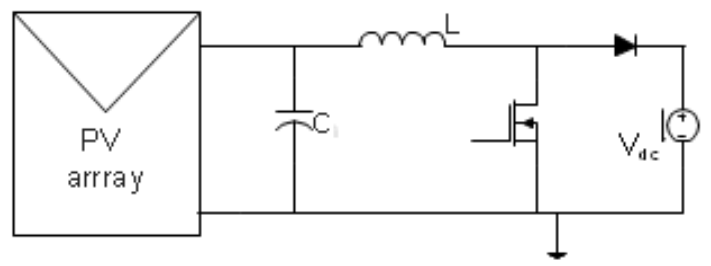

Fig. 8 PV panel + DC/DC power converter electrical schema for the $\mathbf{V Z}$ control approach

The analysis has been performed following the same steps as in the previous section. During the ON semiperiod (d), the voltage and current capacitor is:

$v_{L}=v_{C}=L \frac{d i_{L}}{d t}$

$i_{C}=I_{s c}-\frac{v_{C}}{R_{M P}}-i_{L}=C \frac{d v_{C}}{d t}$

And, during the OFF semi-period, (1-d):

$v_{L}=v_{C_{i}}-V_{d c}=L \frac{d i_{L}}{d t}$

$i_{C}=I_{s c}-\frac{v_{C}}{R_{M P}}-i_{L}=C \frac{d v_{C}}{d t}$

Applying charge and volt-second balances in the inductor and capacitor, respectively, next equations are obtained:

$\dot{i_{L}}=\frac{v_{C}}{L}-\frac{V_{d c} \cdot(1-d)}{L}$
$\dot{v_{C i}}=\frac{1}{C} \cdot\left(I_{s c}-\frac{v_{C}}{R_{M P}}-i_{L}\right)$

Considering $\mathrm{C}_{\text {in }}$ voltage as the system output, system matrix are:

$\begin{aligned} A & =\left[\begin{array}{cc}0 & \frac{1}{L} \\ -\frac{1}{C} & -\frac{1}{C \cdot R_{M P}}\end{array}\right] \\ B & =\left[\begin{array}{ccc}-\frac{V_{d c}}{L} & 0 & \frac{1-d}{L} \\ 0 & \frac{1}{C} & 0\end{array}\right] \\ X & =\left\lfloor\begin{array}{c}i_{L} \\ v_{C}\end{array}\right\rfloor, U=\left[\begin{array}{c}d \\ I_{s c} \\ V_{d c}\end{array}\right], C=\left[\begin{array}{l}0 \\ 1\end{array}\right], D=\left[\begin{array}{l}0 \\ 0 \\ 0\end{array}\right]^{T}, Y=\left[v_{C i}\right]\end{aligned}$

The equilibrium point can be found using (29) and (30):

$V_{C}=V_{d c} \cdot(1-D)$

$I_{L}=I_{s c}-\frac{V_{C}}{R_{M P}}$

In this case, a PID controller has been designed to regulate the input capacitor voltage and therefore, the PV panel output voltage. In this case, design specifications are 0.707 damping factor and $10 \mathrm{kHz}$ closed loop bandwidth. These requirements guarantee a closed-loop gain lower than $0 \mathrm{~dB}$ around the switching frequency value [4].

$G_{C 3}(s)=1.971 \times 10^{-5} \frac{s^{2}+6.4 \times 10^{4} s+1.6 \times 10^{9}}{s}$ 
In this case, the following transfer functions are required:

- $\mathrm{T}_{\mathrm{VVref}}$ : reference-to-input capacitor voltage transfer function

- $\mathrm{T}_{\mathrm{VIsc}}$ : short-circuit current-to-input capacitor voltage transfer function

- $\mathrm{T}_{\mathrm{ViVdc}}$ : output voltage-to-input capacitor voltage transfer function

Closed-loop gains of these transfer functions are represented in Fig. 9. Again, the reference voltage is accurately tracked in the desired frequency range; i.e. up to $10 \mathrm{kHz}$. The short-circuit current and output voltage disturbances are correctly rejected assuring -85.65 and $-69.97 \mathrm{~dB}$ respectively.

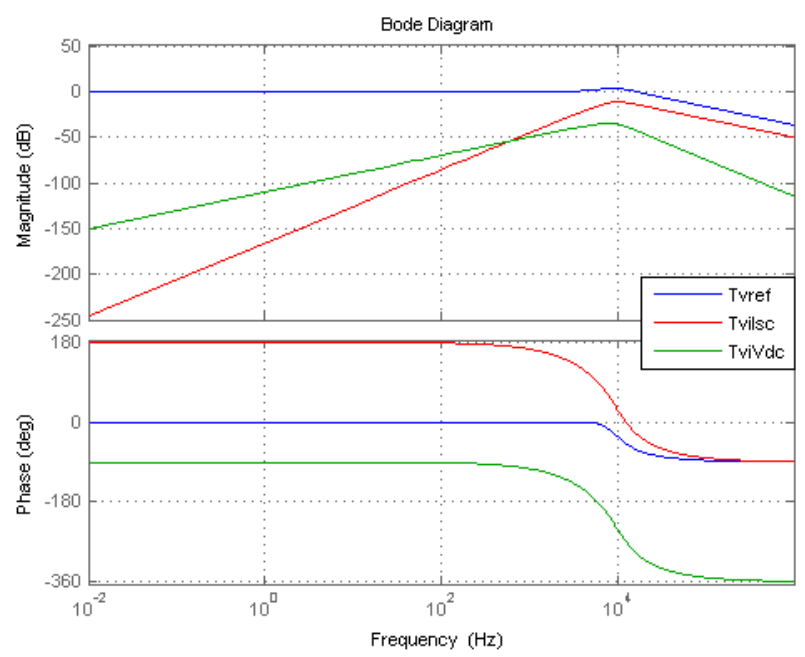

Fig. 9 Closed-loop gain frequency responses for the VZ control approach

\section{Simulations of the presented models.}

In this section, some PSIM circuital simulations have been performed in order to validate previous controllers and models. Both controllers have been optimized for the most critical case. The worst case considers the IZ control of the bulk capacitor DC voltage value, owning $100 \mathrm{~Hz}$ oscillation.

Furthermore, a non-linear PV panel model has been used [7]. Then, PV panel input is based on a periodic irradiance pattern shown in Fig. 10.

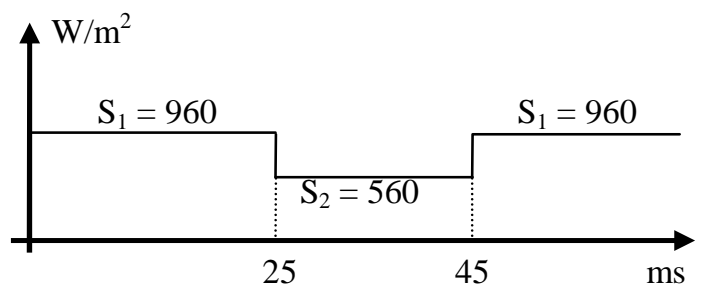

Fig. 10 Irradiance pattern

Bulk capacitor is imposed to $22 \mathrm{uF}$. This capacitor causes an undesired oscillation which might be up to $30 \%$ of the DC voltage. The chosen control MPPT (Maximum Power Point Tracking) strategy is based on the Perturb and Observe (P\&O) algorithm. This technique allows obtaining the PV panel maximum power point [8].

Fig. 11 depicts the system simulation considering the two loops control, owning $\mathrm{G}_{\mathrm{C} 1}-\mathrm{G}_{\mathrm{C} 2}$ controllers, explained in section II. In the top part of this figure, it can be observed the right tracking of the MPPT reference, $V_{\text {MPPT }}$ by the PV panel voltage, $\mathrm{V}_{\mathrm{PV}}$. Moreover, the center parts of the last figure represents the effect of disturbances in the Bulk capacitor voltage and in the PV panel output current, depicted by the short-circuit current. It can be observed that $\mathrm{V}_{\mathrm{PV}}$ recovers accurately the MPPT reference. Moreover, irradiance disturbance are quickly rejected. The bottom part depicts the correct MPPT tracking according to Fig. 4.

Fig. 12 shows a zoom view $(11 \mathrm{~ms}<\mathrm{t}<18 \mathrm{~ms})$ of the previous figure. This figure details settling time (around $350 \mu \mathrm{s})$. It can be observed a small oscillation in the PV panel output power due to the operation circuit and MPP tracking $(50 \mathrm{~mW}, 0.12 \%$ of the maximum power).
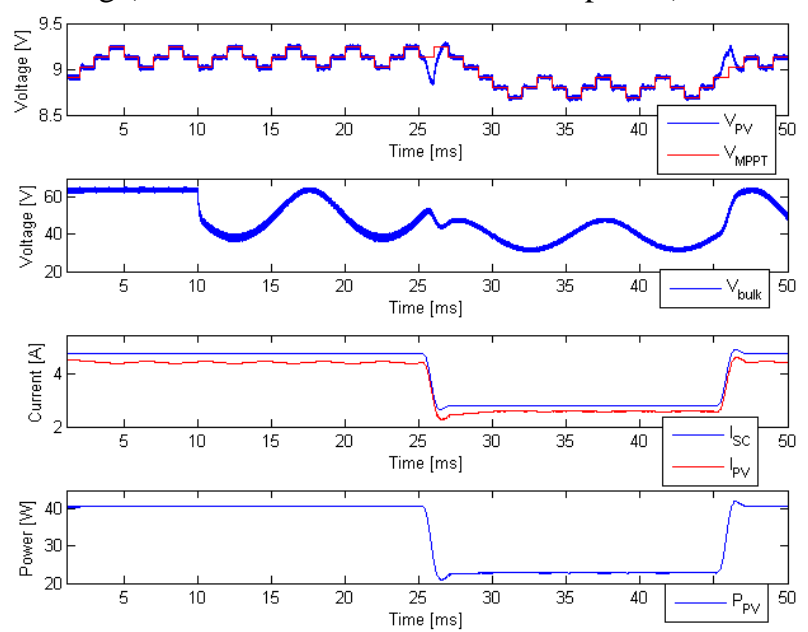

Fig. 11 Simulation results for the IZ control case
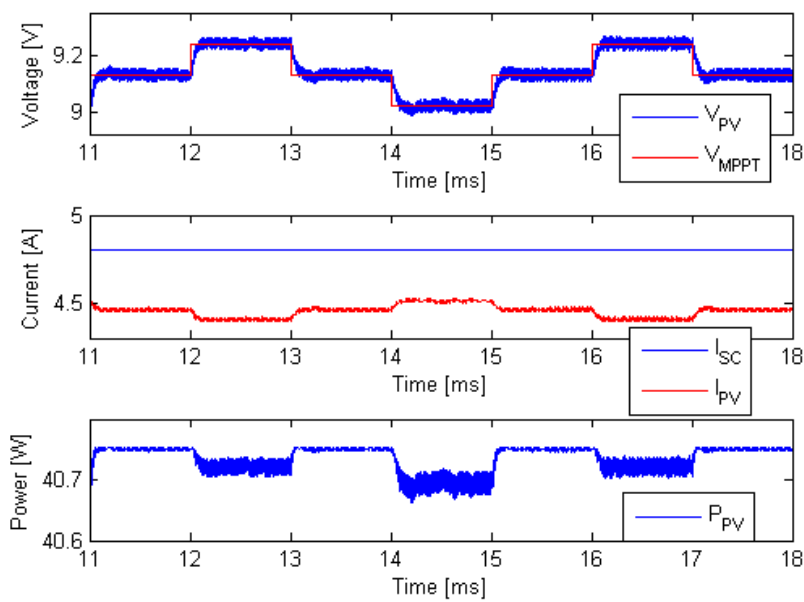

Fig. 12 Detail of the simulation results for the IZ control case

Fig. 13 illustrates the system using $\mathrm{G}_{\mathrm{C} 3}$ as it was shown in section III; i.e. using a VZ control approach to regulate bulk capacitor DC voltage. In this figure, it is shown that the MPP reference is properly tracked as well as disturbances are rejected. 

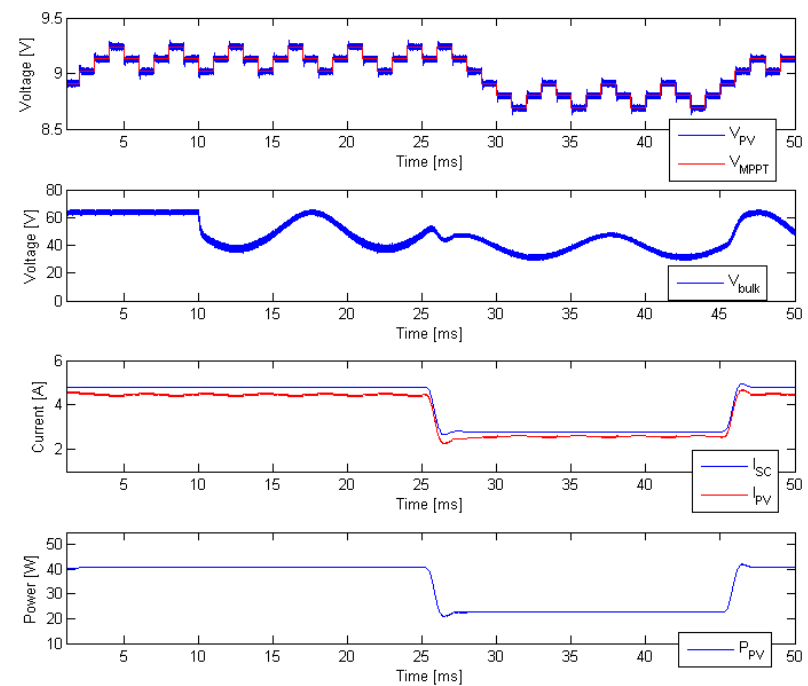

Fig. 13 Simulation results for the VZ control case

Fig. 14 represents a zoom view of previous Fig. 13 in the $11 \mathrm{~ms}<\mathrm{t}<18 \mathrm{~ms}$ time interval. The $\mathrm{V}_{\mathrm{PV}}$ settling time is now $160 \mu \mathrm{s}$ and the oscillation in the output power owns the same value than in the preceding case. The controller, $\mathrm{G}_{\mathrm{C} 3}$, has higher disturbance rejection than in the cascaded controller. This is due to the disturbance owns a frequency range in-between $0-600 \mathrm{~Hz}$. As a result, the higher $\mathrm{G}_{\mathrm{C} 3}$ bandwidth allows a more efficient compensation.
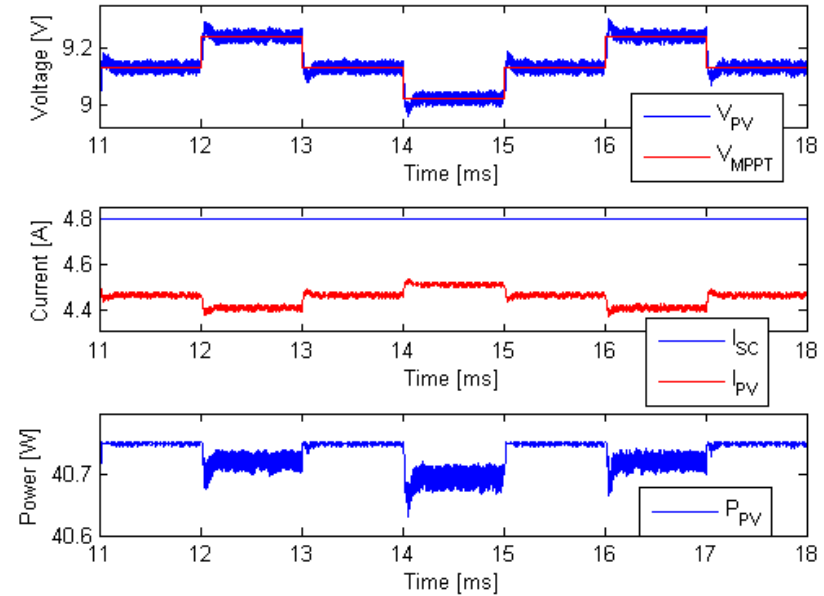

Fig. 14 Detail of the simulation results for the VZ control case

\section{Conclusions}

Future high worldwide request for supply energy makes PhotoVoltaic (PV) energy a potential candidate to replace pollutant power sources for both standalone and gridconnected systems.(already cited in the introduction)

This paper proposes a modeling of a full PV system composed by a PV panel associated to a power conversion stage. This full-system modeling allows an easier design of advanced control strategies to regulate input and output power converter capacitor voltages and therefore, the maximum power delivered by the PV panel. For that matter, two control strategies have been parsed and simulated. These control laws are based on "VZ" and "IZ" control techniques to regulate the Bulk capacitor DC voltage. Furthermore, both control strategies are associated to a P\&O MPPT algorithm in order to obtain the maximum power point of the PV panel. This cascaded control strategy allows obtaining an accurate model of the PV power conversion chain presented in Fig. 1.

The mathematical analysis and circuital simulations of this full-system PV model validates the design process. Moreover, simulations show that the proposed control strategies reject properly input (irradiance) and output (inverter) disturbances affecting the bulk capacitor voltage. As a result, oscillations caused by using a nonelectrolytic capacitor are mitigated.

\section{References}

[1] N. Femia, G. Petrone, G. Spagnuolo and M. Vitelli, "A Technique for Improving P\&O MPPT Performances of Double-Stage Grid-Connected Photovoltaic Systems", IEEE Transactions On Industrial Electronics, vol. 56, no. 11, pp. 4473-4482 November 2009.

[2] S. Liu and R. A. Dougal, "Dynamic multiphysics model for solar array," IEEE Trans. Energy Conv., vol. 17, no. 2, pp. 285-294, Jun. 2002.

[3] N. Femia, D. Granozio, G. Petrone, G. Spagnuolo, M. Vitelli, "Optimized One-Cycle Control in Photovoltaic Grid Connected Applications", IEEE Transactions On Aerospace And Electronic Systems, vol. 42, no. 3, pp. 954972, July 2006.

[4] E. Vidal-Idiarte, L. Martinez-Salamero, J. Calvente and A. Romero, "An $\mathrm{H} \infty$ Control Strategy for Switching Converters in Sliding-Mode Current Control", IEEE Transactions On Power Electronics, vol. 21, no. 2, pp. 553556, March 2006.

[5] R. Leyva, L. Martínez-Salamero, H. Valderrama-Blavi, J. Maixé, R. Gira and F. Guinjoan, "Linear State-Feedback Control of a Boost Converter for Large-Signal Stability", IEEE Transactions On Circuits And Systems-I: Fundamental Theory And Applications, vol. 48, no. 4, pp. 418-424, April 2001.

[6] P. Midya, P. Krein, R. Turnbull, R. Reppa, and J. Kimball, "Dynamic maximum power point tracker for photovoltaic applications," in Proc.27th IEEE Power Electronics Specialists Conf., vol. 2, pp. 1710-1716, Jun. 1996.

[7] G. Petrone, G. Spagnuolo, M. Vitelli, "Analytical model of mismatched photovoltaic fields by means of Lambert Wfunction”, Solar Energy Materials \& Solar Cells, vol. 91, pp. 1652-1657, July 2007.

[8] N. Femia, G. Petrone, G. Spagnuolo and M. Vitelli, "Optimization of Perturb and Observe Maximum Power Point Tracking Method", IEEE Transactions On Power Electronics, vol. 20, no. 4, pp. 963-973, July 2005. 